\title{
A IMAGEM DO ESPORTE NA PROPAGANDA: UMA ANÁLISE DISCURSIVA
}

\author{
Israilda do Vale Franca ${ }^{1}$; Girlene Lima Portela ${ }^{2}$ \\ 1.Bolsista PROBIC-UEFS, graduanda em Letras Vernáculas, Universidade Estadual de Feira de Santana, e -mail: \\ ildabk@hotmail.com \\ 2.Orientadora, departamento de Letras e Artes, Universidade Estadual de Feira de Santana, e-mail: \\ falecom@girleneportela.com.br
}

PALAVRAS- CHAVES: texto; discurso; imagem.

\section{INTRODUÇÃO}

O texto possui uma definição ampla e se apresenta de diferentes maneiras, não se limitando unicamente à modalidade verbal, pois existe uma grande variedade de textos imagéticos, inseridos no nosso cotidiano. Nesse sentido, pode-se argumentar que, a todo momento estamos produzindo textos seja por meio de uma peça teatral, de uma obra de arte, de um gif, de um meme, de uma música, etc, já que o texto está automaticamente envolvido na comunicação humana, desde a época primitiva. No tempo das cavernas, o homem já produzia textos (imagens) e era através deles que a comunicação acontecia, como pode ser constatado em Santaella e Noth $(2015$, p.13), quando eles afirmam que as "imagens têm sido meios de expressão da cultura humana desde as pinturas pré-históricas das cavernas, milênios antes do aparecimento do registro da palavra pela escritura". Também confirmado por Dondis (2007), quando ensina que no nosso primeiro contato visual com o mundo, passamos a sistematizar nossas necessidades e nossos prazeres, nossas preferências e nossos temores, com base naquilo que vemos. Ou naquilo que desejamos ver.

Como vimos, antes mesmos do surgimento da escrita, as imagens já existiam como um sistema de comunicação usada pelo ser humano. Essa descrição, porém, é apenas a ponta do iceberg, e não dá de maneira alguma a medida correta do poder e da importância que o sentido visual exerce sobre nossa vida. Nós o admitimos sem nos darmos conta de que ele pode ser aprimorado no processo básico de observação, ou expandindo até converter-se num incomparável instrumento de comunicação humana. Aceitamos a capacidade de ver da mesma forma como a vivenciamos — sem esforço. (Cf. Dondis, op. cit.)

Dessa maneira, observa-se que as imagens exercem bastante influência sobre a vida das pessoas, já que elas são um dos mais importantes meios de comunicação usados pelo homem. As imagens, ao serem utilizados com esse intuito, também são capazes de manipular as pessoas. $O$ poder manipulador das mensagens pode também originar-se de uma aptidão semiótica para mentir, isto é, fazer afirmações com a finalidade de iludir, conforme alertam Santaella e Noth (2015).

Baseando-nos nessa capacidade manipulativa, inerente ao ser humano; no poder manipulador das imagens, que ocorre em diferentes áreas de interesses, a exemplo da propaganda, que utiliza-se não apenas do texto verbal, mas principalemnte do texto imagético para comunicar-se, nosso estudo tem como objeto principal o gênero textual propaganda, o qual faz o uso de vários tipos de imagens em suas propagandas, com a finalidade de propagar sua mensagem, muitas vezes iludindo seus eventuais consumidores, ao veicular as benesses de seus produtos. Nessa perspectiva, é bastante usual os publicitários lançarem mão de imagens esportivas em suas propagandas, uma vez que o fazer esportivo normalmente está atrelado à beleza física, ao bem-estar físico e emocional dos sujeitos, além de ser usado no tratamento de diversas doenças. 
Nesse sentido, esta comunicação tem por objetivo apresentar alguns dados de nosso estudo, que busca, dentre outros objetivos, averiguar como as propagandas fazem o uso de imagens esportivas para propagar a marca e o produto de determinada empresa. Com isso, visamos compreender como a imagem do esporte se comporta nas propagandas e até que ponto o discurso imagético esportivo influencia no poder de escolha do consumidor. Diante disso, analisamos os ditos e os não ditos presentes nos discursos estéticos e verbais de algumas propagandas para entender como as imagens esportivas presentes nos rótulos da embalagem de determinado produto influencia na compra desses produtos.

Para amparar esse estudo, nos baseamos em alguns teóricos que se debruçaram sobre os estudos acerca da imagem na sociedade atual, como é o caso de como Portela (1999; 2012), para compreender as diferentes concepções de texto e de imagens, Ducrot (1987) que discorre sobre os ditos e os não ditos, além de Santaella e Noth (2015), Donis (2007) que abordam sobre diferentes tipos de imagem e a importância delas para a comunicação, dentre outros teóricos.

\section{METODOLOGIA}

Para esta pesquisa, foram selecionadas algumas propagandas situadas em diferentes contextos socio-históricos referentes a várias marcas de produtos de diferentes empresas, como as sandálias Havaianas, o cigarro Hollywood, os sabonetes Lifebuoy e Rexona, a cerveja Kaiser, um complemento alimentar, o Biotônico Fontoura, além do achocolatado Nestlé. Neste estudo, foi utilizado o método de pesquisa descritivo, com base na semiótica e na análise do discurso de linha francesa. $\mathrm{Na}$ análise do discurso verbal (enunciado), foi utilizada a polifonia (as vozes do enunciado), apresentadas por Bakhtin (2008), Ducrot (1987) e defendidos por Portela (1999). Considerando-se a extensão deste texto não apresentaremos análises da propaganda, mas discutiremos os dados encontrados em algumas das 10 (dez) análises realizadas no corpus da pesquisa.

\section{RESULTADOS E DISCUSÕES}

Durante a realização das análises, de algumas propagadas (já ditas acima) buscamos perseguir nosso objetivo, o qual visava conhecer como os publicitários se utilizavam de imagens esportivas para atingir seu público-alvo, na busca da venda de produto ao consumidor. Nesse sentido, pode ser constatado que essa tipologia de imagem usadas pelos publicitários, presente no rótulo do produto visa convencer as pessoas, a aceitação de suas ideias por meio dos discursos verbais, estéticos e pictóricos.

Ao realizar a análise de algumas propagandas como: o cigarro da Hollywood, a sandália da havaianas, o complemento alimentar, Biotônico Fontoura e o sabonete Rexona, concluímos que além dessas marcas de produtos usarem a imagem de atletas fortes, saudáveis para fazer referência aos efeitos de seus respectivos produtos, também se apoiavam em um discurso pictórico, usavam as cores para atrair os seus consumidores, seduzi-los por meio da pintura, as cores mais frequentes nessas propagandas foram: o branco, o azul, o verde e o amarelo que correspondem as pinturas da bandeira nacional do Brasil e que apareciam nas vestes do atleta com intuito de convencer o consumidor que todo aquele que desejar, ser forte, saudável, aceito socialmente como os esportistas do rótulo do produto deve fazer o uso de tais produtos.

Por outro lado, esse discurso pictórico, também faz remissão a natureza, ao ouro, aos mares e o céu brasileiro como se fosse um convite para as pessoas conhecerem, desbravarem as terras brasileiras por meio da aquisição do produto, ou seja, induz os sujeitos a acreditar que todo aquele que comprar o produto de respectiva marca vai possuir o ouro, a natureza, o 
ceú e os mares brasileiros. Muito embora sejam propagandas situadas em diferentes períodos socio-histórico podemos afirmar que seus discursos imagéticos e pictóricos retomam as mesmas ideias e buscam o mesmo objetivo que é a venda do produto por das imagens e das cores.

Já, as propagandas de sabonete da marca lifebuoy e a de cerveja da marca Kaiser não apresentam um discurso pictórico, como as campanhas descritas acima, pois contem apenas as cores preto e branco e nesses tipos de propagandas que apresentam uma pintura monocromática as imagens, tem como objetivo principal reforçar o discurso verbal dos enunciados das campanhas, comprovar por meio do discurso imagético o efeito de determinado produto na vida de quem os consomem. Como foi averiguado na análise de tais propagandas

Das 10 (dez) propagandas analisadas 9 (nove) trazem a imagens de atletas aliadas aos benefícios de seus produtos, já que o esporte é usado no tratamento de diversos tipos de doenças, além de ajudar no desempenho físico e emocional dos sujeitos envolvidos nas práticas esportivas, sendo assim a imagem do atleta é usada para iludir, enganar as pessoas, pois tais produtos, possuem substancias altamente nocivas para a saúde tanto do atleta como das pessoas comuns e que não são divulgados em suas campanhas. Já, a propaganda da lifebuoy apropria-se da fotografia de família jogando vôlei de praia com propósito, de vender o seu sabonete, pois tal produto, é destinado a um público específico, as mulheres que ocupam a posição de mãe diante da sociedade, pois elas tem maior poder de decisão no momento da escolha da produto, e principalmente tratando-se de um produto que "garantir" a proteção de sua família dessa maneira, a fotografia da família jogando vôlei de praia serve para ratificar o enunciado verbal da propaganda.

Por sua vez, o discurso verbal das propagadas, sob análise apresentavam sempre o logotipo da marca, o nome do produto e seus respectivos efeitos é natural os publicitários usarem enunciados como "o mais completo fortificante" (Biotonico Fontoura), " havainas. A melhor sandália de borracha" (havaianas) etc., com o intuído de convencer o consumidor que o produto em destaque é superior, melhor que as marcas correntes no mercado e por isso, as pessoas devem optar por tal marca de produto.

Por outro lado, somente duas propagandas apresentaram a modalidade esportiva escrita verbalmente em seus enunciados que foram: a sandália da havainas " surfin. Havainas Brasil e a de achocolatado da Nestlé "Thaísa seleção de vôlei" as outras propagandas analisadas neste corpus apresentam o esporte apenas nas imagens sem alongar-se ao discurso verbal.

Sendo assim, podemos considerar a partir, dos estudos e das análises feitas que o uso de imagens nesse gênero textual (propaganda), visa persuadir o consumidor de determinada marca a comprar o produto veiculado, pela sedução das cores, discursos subjacentes, estética, crença e valores difundidos pela sociedade, representando, muitas vezes, riscos à saúde, dentre outros malefícios ao se consumir algo apenas baseado nas informações da indústria propagandística.

\section{CONSIDERAÇÕES FINAIS}

O trabalho sobre o estudo do texto imagético dentro das propagandas é enriquecedor, pois as imagens propagandísticas estão presentes na sociedade nos mais diversos locais, visto que a todo o momento somos bombardeados com uma propaganda seja de cunho político, persuasiva, religiosa etc. Em virtude disso, a Análise do Discurso é bastante relevante para a compreensão dos dizeres e não dizeres que circundam esse gênero textual/discursivo.

Dessa maneira, ao compreender os ditos e os não-ditos presentes nos discursos imagéticos propagandístico, entender-se-á que as formas de dizeres é intencional, e essa 
intenção é fundamental para a venda do produto, pois busca-se antes de tudo ressaltar as qualidades da mercadoria sem se preocupar com malefícios que podem ocasionar, sendo assim é de suma importância entender tais princípios para não se deixar seduzir pelos discursos estéticos e verbais das propagandas esportivas, é preciso atentar-se para os riscos que o consumo ou o uso que os produtos possam ocasionar.

Nesse sentido, esse trabalho ajudou a entender que a imagem não é simplesmente para completar o texto, essas também são um texto que apresentam diferentes sentido e mesmo que não sejam acompanhadas por um texto verbal conseguem estabelecer comunicação, transmitir para os sujeitos seus conceitos e suas ideologias.

\section{REFERENCIAS:}

BAKHTIN Michael. Discurso na arte e Discurso na vida (sobre a poética sociológica). Trad. De Carlos Alberto Faraco e Cristovão Tezza [para fins didáticos]. Versão da língua inglesa de I.R. Titunik, a partir do original russo 1926.

DUCROT, Oswald. O dizer e o Dito; revisao tecnica da tradução Eduardo Guimarães.Campinas.- Campinas, SP: Pontes 1987.

DUCROT,Oswald. Princípios da Enunciação Semântica, (Dizer e não Dizer); Hermann, Paris, editora Cultrix 1972.

SANTAELLA, Lucia; NOTH, Winfried. Imagem: cognição, semiótica, midia; 1. Edição, São Paulo, 1997- 9. Reimpressão, 2015.

PORTELA, Girlene Lima. Da tropicalia à marginalia: o intertexto ("a que será que se destina?") na produção de Caetano Veloso: EGBA: Universidade Estadual de Feira de Santana, 1999. 